NOTES

\title{
Thermal Degradation of Sequence-Ordered Copolymers Containing Methacrylic Acid Units
}

\author{
Yoshihito InaI, ${ }^{*}$ Shin-ichiro Kato, Tadamichi Hirabayashi, \\ and Kenji YoKaTA \\ Department of Materials Science and Engineering, Nagoya Institute of Technology, \\ Gokiso-cho, Showa-ku, Nagoya 466, Japan
}

(Received May 20, 1994)

\begin{abstract}
KEY WORDS Thermal Degradation / Sequence-Ordered Copolymer / Methacrylic Acid / Copolymer-Sequence Effect /
\end{abstract}

The thermal degradation of acid-polymers containing carboxyl groups has been widely studied. ${ }^{1-6}$ The degradation process starts with the formation of cyclic-and/or linear-type anhydrides. Since anhydride formation is a bimolecular reaction between carboxyl groups, the thermal stability of an acid-polymer depends on how carboxyl groups appear on the polymer main-chain. Syndiotactic and atactic polyacrylic acids show different thermal stabilities. ${ }^{2}$ Also, ethylene(E)-methacrylic acid (MAA) statistical copolymers show that the formation of cyclic-type anhydride (1) becomes more desirable than that of linear-

We have studied copolymer-sequence effects on physical properties using sequence-ordered copolymers. ${ }^{7-12}$ How the thermal stability of an acid-copolymer depends on the copolymer sequence, i.e., on differences in the space between the neighboring carboxyl groups on type anhydride (2), with increasing MAA content. $^{3}$<smiles>[CH2+]C1(C)CCC(C)(C)C(=O)O1</smiles>

(1)

its polymer main-chain should be studied. In the present communication, to reveal this point, we investigated the thermal degradation of two sequence-ordered copolymers:alternating $(1: 1)$ E-MAA copolymer I and periodic (2:1) E-MAA copolymer II.<smiles>CCCCCC(C)(C)C(=O)O</smiles>

II 


\section{EXPERIMENTAL}

For comparison, poly(methacrylic acid) (PMAA) was prepared by free radical polymerization of MAA with 2,2'-azobisisobutyronitrile at $60^{\circ} \mathrm{C}$ in methanol.<smiles>CCCC(C)(C)C(=O)OC</smiles>

1

Copolymer 2 was prepared and its sequenceordered structure was determined by the same procedure as described previously. ${ }^{12}$ Copolymer 1 was prepared as follows. 2-Methyl-2,4pentadienoate 3 was polymerized by the group
Sequence-ordered copolymers I and II were obtained by saponifying the corresponding esters, i.e., alternating (1:1) E-methyl methacrylate (MMA) copolymer 1, and periodic (2:1) E-MMA copolymer 2, respectively.

2

transfer polymerization method that gives polymer 4 having only 1,4-unit. ${ }^{13}$ Polymer 4 was refluxed in toluene containing $p$-toluenesulfonhydrazide for $24 \mathrm{~h}$ to give copolymer 1 .<smiles></smiles>

3

Figures 1(a) and (b) show the ${ }^{1} \mathrm{H}$ and ${ }^{13} \mathrm{C}$ NMR spectra of copolymer 1 . The ${ }^{13} \mathrm{C}$ NMR spectrum showed only six peaks assignable to each carbon in the single repeating unit. The preparation and characterization of copolymer 1 will be described in detail elsewhere.

The methoxyl groups in their side chains were converted to hydroxyl groups by standard saponification reactions. The typical procedure is as follows. Copolymer 1 (or 2) (4 mmol with respect to MMA unit) was dissolved in 1,4dioxane $(50 \mathrm{ml})$, and methanol $(8 \mathrm{ml})$, and then water $(8 \mathrm{ml})$ containing $\mathrm{KOH}(15 \mathrm{~g}, 0.23 \mathrm{~mol})$ were added to the solution. The mixture was stirred at $60^{\circ} \mathrm{C}$ for $50-60 \mathrm{~h}$. After evaporation of the solvents, methanol $(70 \mathrm{ml})$ and water $(8 \mathrm{ml})$ containing the above amount of $\mathrm{KOH}$ were added to the residue. The mixture was stirred at $60^{\circ} \mathrm{C}$ for $90-100 \mathrm{~h}$, and then cooled over an ice bath. A white solid was precipitated

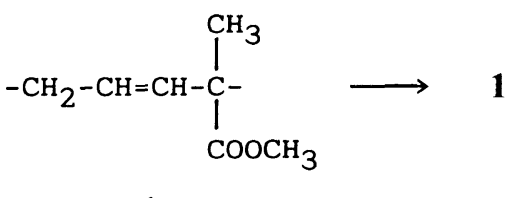

4

by adding $\mathrm{HCl}$ until solution $\mathrm{pH}$ was $\mathrm{ca}$. 1 . The solid was reprecipitated three times by using methanol-water system, and dried in vacuum. The obtained copolymers gave the corresponding ${ }^{1} \mathrm{H}$ NMR spectra where methoxyl protons completely disappeared and carboxyl protons appeared at ca. $12 \mathrm{ppm}$ (e.g., as shown in Figure 1(c)). This indicates that side-chain saponification completely proceeded. Further, copolymers I and II partially changed to the corresponding methyl esterified ones by the diazomethane method. ${ }^{14}$ The esterified copolymers showed essentially the same ${ }^{1} \mathrm{H}$ NMR spectra and molecular weights as copolymers 1 and 2 , respectively. Thus, the side-chain reaction proceeded quantitatively without chain scission or gelation.

${ }^{1} \mathrm{H}(200 \mathrm{MHz})$ and ${ }^{13} \mathrm{C}(50 \mathrm{MHz})$ nuclear magnetic resonance (NMR) spectra were recorded on a Varian XL-200 spectrometer. 

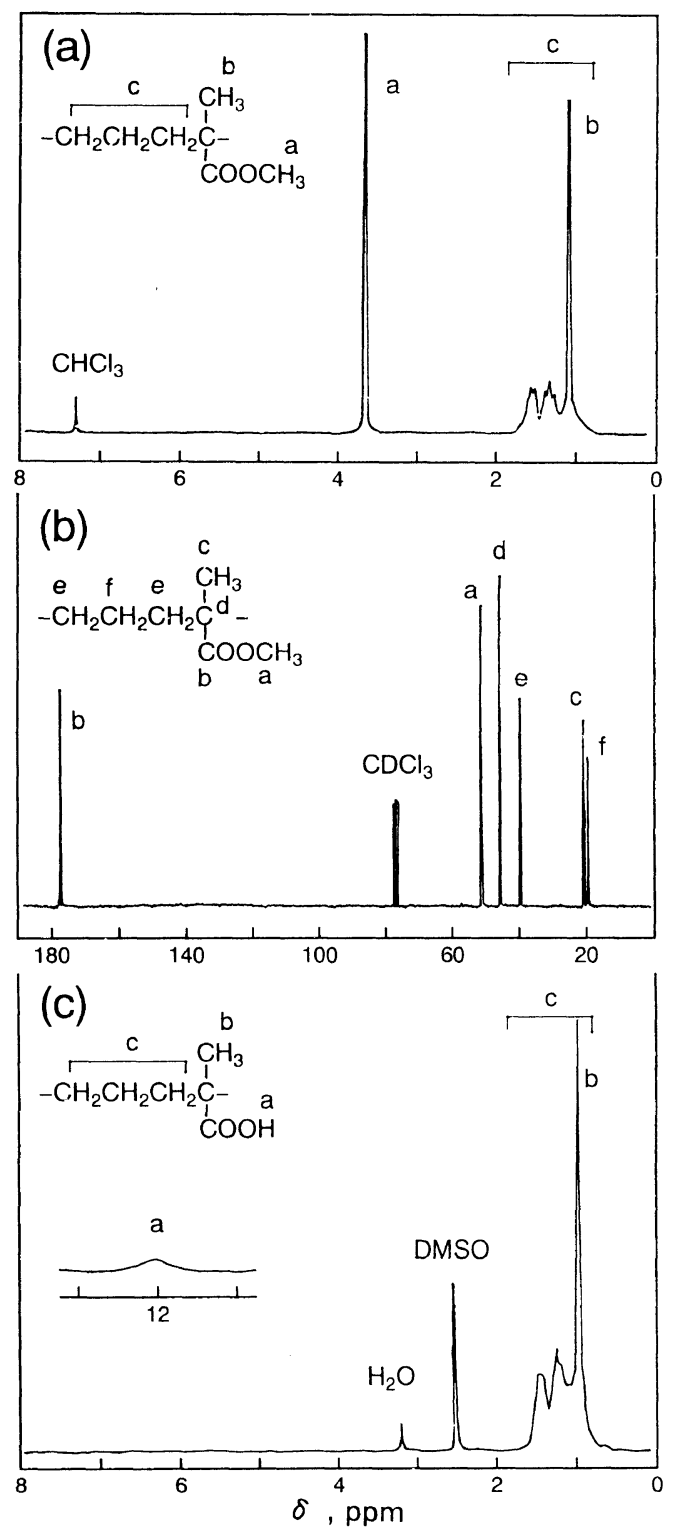

Figure 1. (a) ${ }^{1} \mathrm{H}$ and (b) ${ }^{13} \mathrm{C}$ NMR spectra of copolymer 1 in $\mathrm{CDCl}_{3}$; (c) ${ }^{1} \mathrm{H}$ NMR spectrum of copolymer $\mathrm{I}$ in dimethyl sulfoxide- $d_{6}$ (DMSO).

The pulse sequences are as follows: for ${ }^{1} \mathrm{H}$, 12.4- $\mu$ s pulse width, 5 -s acquisition time, and 8 -s interval; for ${ }^{13} \mathrm{C}, 8-\mu$ s pulse width, 0.8 -s acquisition time, and 1-s interval. Gel permeation chromatography (GPC) was performed in tetrahydrofuran at $40^{\circ} \mathrm{C}$ on a Tosoh HLC

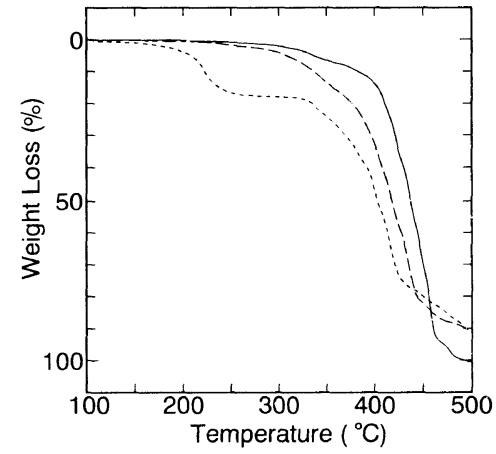

Figure 2. TG curves of PMAA (----), I (--), and II (-).

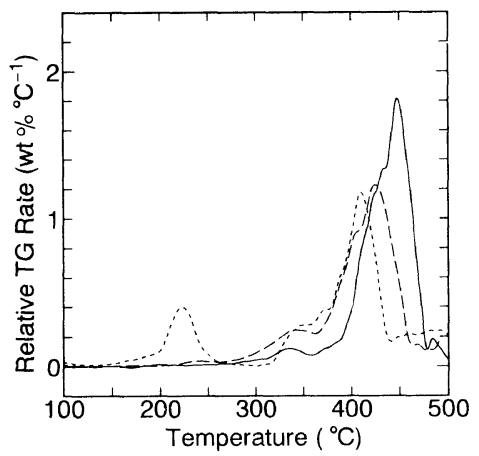

Figure 3. Relative rates of weight loss for PMAA (--.-), I (- - ), and II (- $)$.

803D with G5000-, G4000-, G3000-, and G2000-HLX columns in series. The chromatograms were measured for the three copolymers esterified with diazomethane, and were calibrated by polystyrene standards to calculate $M_{n}: 6.6 \times 10^{4}$ for I, $8.7 \times 10^{4}$ for II, and $5.3 \times 10^{4}$ for PMAA. The thermal degradation behavior of the polymers was studied by thermogravimetry-differential thermal analysis (TG-DTA) on a Seiko I TA Station TG/DTA 220. A sample (ca. $10 \mathrm{mg}$ ) taken in an open-platinous pan was heated under air from 20 to $500^{\circ} \mathrm{C}$ at a rate of $10^{\circ} \mathrm{C} \mathrm{min}^{-1}$.

\section{RESULTS AND DISCUSSION}

Figure 2 shows the TG curves for PMAA, copolymers I and II, and Figure 3 shows their 
corresponding TG rate curves. PMAA showed two degradation regions. The first region started at ca. $140^{\circ} \mathrm{C}$ and ended at $c a .260^{\circ} \mathrm{C}$ with a maximum degradation rate at $220^{\circ} \mathrm{C}$. The second region started at $c a .310^{\circ} \mathrm{C}$ with a maximum degradation rate at $410^{\circ} \mathrm{C}$. Such behavior agreed well with that reported by Ho et al. ${ }^{1}$ They claim that the first degradation region corresponds to the conversion of PMAA to polymethacrylic anhydride and the second region corresponds to the thermal degradation of the polyanhydride.

Grand et al. $^{4}$ claim that PMAA having a head-to-tail structure forms in the first degradation region the two anhydrides as indicated before, i.e., a cyclic-type (1) (sixmembered ring) or a linear-type (2). The cyclic-type dominates over the linear-type in the case of PMAA. ${ }^{1,4,5}$

Copolymers I and II showed mainly two degradation regions, which appeared not as clearly as in PMAA. For copolymer I, the first region started at $c a .200^{\circ} \mathrm{C}$ with a maximum rate at $340^{\circ} \mathrm{C}$, and the second one started at ca. $350^{\circ} \mathrm{C}$ with a maximum rate at $425^{\circ} \mathrm{C}$. For copolymer II, the first region started at $c a$. $250^{\circ} \mathrm{C}$ with a maximum rate at $335^{\circ} \mathrm{C}$, and the second one started at $c a .350^{\circ} \mathrm{C}$ with a maximum rate at $450^{\circ} \mathrm{C}$.

On comparing the thermal degradation behavior of these three polymers, we can see the most striking difference between thermal degradations of PMAA and the sequenceordered copolymers. That is, copolymers I and II showed the first degradation regions at higher temperatures than PMAA. Obviously, copolymers I and II are more stable than PMAA, i.e., more difficult to form anhydrides than PMAA. The reason for this should be the differences in space between the neighboring carboxyl groups on their polymer main chains. If the dehydration between the neighboring carboxyl groups occurs in copolymers I and II, the resulting anhydrides should have eight- and ten-membered ring structures, respectively. That such cyclic anhydrides are thermodynami cally much more unstable than six-membered cyclic anhydride has been proven in dicarboxylic acids. ${ }^{15}$ E-MAA statistical copolymers containing $6.7-29 \mathrm{~mol} \%$ MAA units formed both linear and six-membered cyclic anhydrides by heating at $140-160^{\circ} \mathrm{C} .^{3}$ With decreasing MAA content, the formation of the linear-type became more desirable than that of the cyclic-type. Thus, the anhydrides formed in copolymers I and II are considered to have the linear-type structure. It should be noted as the sequence-ordered effect that copolymers I and II containing 50 and $33 \mathrm{~mol} \%$ MAA units respectively cannot form a six-membered cyclic anhydride. Consequently, sequence-ordered copolymers I and II showed higher thermal stability than PMAA.

The second degradation regions in copolymers I and II may correspond not only to the thermal degradation of anhydrides formed in the first regions, but to that of the polymer main-chains. Such degradation of main-chains was suggested by the thermal degradation of periodic $(2: 1)$ E-methyl methacrylate copolymer, which has no carboxyl groups, but showed rapid degradation above $c a .350^{\circ} \mathrm{C} .^{12}$

Acknowledgment. This study was supported by a Giant-in-Aid for Cooperative Research (A), the Ministry of Education, Science, and Culture of Japan.

\section{REFERENCES}

1. B. Ho, Y. Lee, and W. Chin, J. Polym. Sci., A, Polym. Chem., 30, 2389 (1992).

2. J. J. Maurer, D. J. Eustace, and C. T. Ratcliffe, Macromolecules, 20, 196 (1987).

3. J. Y. Lee, P. C. Painter, and M. M. Coleman, Macromolecules, 21, 346 (1988).

4. D. H. Grant and N. Grassie, Polymer, 1, 125 (1960).

5. C. A. Fyfe and M. S. McKinnon, Macromolecules, 19, 1909 (1986).

6. M. C. McGaugh and S. Kottle, Polym. Lett., 5, 817 (1967)

7. K. Mori, H. Sumi, T. Hirabayashi, Y. Inai, and K. Yokota, Macromolecules, 27, 1051 (1994).

8. K. Yokota, M. Miwa, T. Hirabayashi, and Y. Inai, Macromolecules, 25, 5821 (1992). 
9. T. Hirabayashi, T. Yamauchi, and K. Yokota, Macromolecules, 24, 4538 (1991).

10. T. Hirabayashi, K. Yamauchi, and K. Yokota, Macromolecules, 24, 4543 (1991).

11. T. Hirabayashi, K. Yamauchi, and K. Yokota, Macromolecules, 23, 935 (1990).

12. K. Yokota and T. Hirabayashi, Macromolecules, 14, 1613 (1981).
13. W. R. Hertler, T. V. RajanBabu, D. W. Ovenall, G. S. Reddy, and D. Y. Sogah, J. Am. Chem. Soc., 110, 5841 (1988).

14. T. Otsu and M. Kinoshita, "Koubunshi Gousei no Jikkenhou," Kagaku-Dōjin, Kyoto, Japan, 1972, p 369.

15. J. W. Hill and W. H. Carothers, J. Am. Chem. Soc., 55, 5023 (1933). 